\title{
Process-based Modelling of a Nearshore Nourishment
}

\author{
Darrell Strauss $^{\dagger^{* *}}$, Guilherme Vieira da Silva ${ }^{\dagger}$, Ana Paula da Silva ${ }^{\dagger}$, Thomas Murray ${ }^{\dagger}$, Gaelle \\ Faivre $^{\dagger}$, and Courtney Wharton ${ }^{\star}$
}

${ }^{\dagger}$ Griffith Centre for Coastal Management Gold Coast, QLD, Australia
* City Assets, Transport and Infrastructure City of Gold Coast, Australia

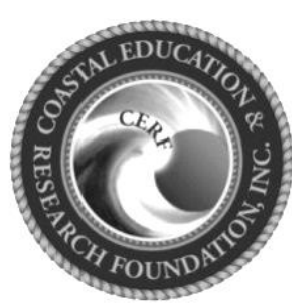

www.cerf-jcr.org

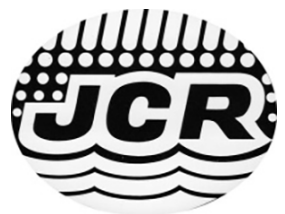

www.JCRonline.org

\begin{abstract}
Strauss, D.; Vieira da Silva, G.; da Silva, A.P.; Murray, T.; Faivre, G., and Wharton, C., 2020. Processbased modelling of a nearshore nourishment. In: Malvárez, G. and Navas, F. (eds.), Global Coastal Issues of 2020. Journal of Coastal Research, Special Issue No. 95, pp. 1297-1302. Coconut Creek (Florida), ISSN 0749-0208.

Beach erosion and recovery morphodynamics are complex physical processes that are difficult to measure, particularly in the surf zone. Hence, with consideration of the respective advantages and limitations of the coastal morphological modelling approach to inform coastal management and climate adaptation strategies, the inclusion of these processes in predictive numerical models requires careful validation and interpretation. The timescale of their investigation dictates the optimal numerical modelling approach that should be applied to simulate and predict beach morphology changes. The level of detail and therefore, process understanding, obtained from numerical modeling ranges from 1D shoreline models to more sophisticated 3D physical process models. Here, we present the application and validation of a 3D process-based model (Delft3D) to simulate the dispersion of a nearshore beach nourishment in the outer surf zone at a highly variable (energy and direction) open coast beach on the east coast of Australia.
\end{abstract}

ADDITIONAL INDEX WORDS: Beach nourishment, shoreline, beach morphodynamics, numerical model.

\section{INTRODUCTION}

Beach nourishment is desirable to maintain coastal amenity for recreation, tourism, protection of infrastructure and other socio-economic benefits. Since the morphodynamics of beach erosion and recovery consists of complex physical processes that are poorly understood and difficult to observe, particularly in the surf zone, the inclusion of these processes in predictive numerical models requires significant validation and hence, careful interpretation of results.

The timescale of investigation or desired information dictates the numerical modelling approach that should be applied to simulate or predict beach morphology changes and the level of detail (i.e. from 1D shoreline models to sophisticated 3D physical process models).

An initial conceptual design of a coastal project such as a beach nourishment and its predicted outcome is often informed by previous interventions and expert knowledge, but the longer term beach response may be further explored using a fixed beach profile (equilibrium profile) or 1D shoreline model. A 1D equilibrium coastal profile model will generally disregard the development and evolution of surf zone sandbars and so their impact on wave dissipation is not properly considered. Nevertheless, useful insights may be gained from applying a shoreline model in the conceptual or evaluation phase of a coastal management strategy (Chang et al., 2018). In particular, where alongshore dispersion

DOI: 10.2112/SI95-250.1 received 31 March 2019; accepted in revision 13 February 2020.

*Corresponding author: d.strauss@griffith.edu.au

${ }^{\circ}$ Coastal Education and Research Foundation, Inc. 2020 and structural controls dominate the morphological evolution of the beach.

Depth-averaged (2DH) models, representing the next level of complexity, simulate shallow water wave and tide dominant circulation, and subsequent sediment transport by horizontal motions in shallow water, quite well with some parameterizations of the vertical processes. This approach is widely used to inform and manage tidal entrance or barrier-breach behavior (Shaeri et al., 2018).

A 3D or quasi-3D model introduces vertical physical processes into the model significantly increasing complexity due to the simulation of processes such as undertow and upwelling. Consideration should always be given to the respective advantages, and limitations, of the coastal morphological modelling approaches currently in use to inform coastal management adaptation strategies in light of the challenge of future climate change.

To demonstrate, this paper presents the application of a $3 \mathrm{D}$ process-based model (Delft3D) to simulate the dispersion of a deliberate nearshore beach nourishment mound over a period of a few months. The nourishment was placed in the active surf zone of Palm Beach, (Gold Coast, Queensland) on the east coast of Australia.

\section{SITE DESCRIPTION}

Palm Beach is located in the City of Gold Coast, Queensland, Australia. It is a micro-tidal, wave-dominated, open coast beach that is periodically exposed to high energy waves from numerous sources including tropical cyclones. The highly variable wave climate of the South East Australian Shelf allows a wide variety 
of sources of wave energy to impact the Gold Coast beaches. These sources include tropical cyclones forming in the Coral Sea, tropical lows occurring in the Coral and Tasman Seas, East Coast Lows (which typically develop closer to shore), anticyclonic intensification (strong 'trade' winds), Southern Ocean lows and southern Tasman lows.

Several complex coastal engineering challenges have arisen since the early 1960's as a result of the exposure to highly variable wave energy throughout the year combined with the high interannual variability of extreme events. One such project involved the trial of a nearshore nourishment of $1.5 \mathrm{Mm}^{3}$ in 1990 (Jackson and Tomlinson, 1990; Smith and Jackson, 1990).

Prior to a particularly active year of storms and cyclones, resulting in widespread and severe erosion in 1967, there was little data available with which to inform coastal protection strategies. In the $50+$ years since there has been a survey program in place collecting ad-hoc surveys of beach profiles, albeit often in conjunction with storm events.

Since 2016 the authors, with the support, and in collaboration with, the City of Gold Coast, Griffith University and the Queensland State government, have been collecting detailed surveys of six sites of up to $2 \mathrm{~km}$ alongshore each, with a spatial resolution of $50 \mathrm{~m}$ between adjacent profiles and approximately monthly temporal spacing. During this time a large beach nourishment project supplied $3 \mathrm{M} \mathrm{m}^{3}$ of marine sand from offshore into the surf zone by a combination of rainbowing and bottom dumping. Sand was added to the antecedent profile at depths approximately $-4 \mathrm{~m}$ to $-9 \mathrm{~m}$ below MSL.

\section{METHODS}

The hydrographic survey dataset collected immediately following the beach nourishment at Palm Beach (Figure 1) was used to initiate a 3D numerical sediment transport model to be validated against a subsequent survey (Figure 2). A deep water wave buoy (at $70 \mathrm{~m}$ depth) was used as input to the model at the offshore (SWAN) wave model boundary and a nearshore Acoustic Doppler Current Profiler (ADCP) (at $7 \mathrm{~m}$ depth) provided nearshore wave, currents and water level data for validation in the hydrodynamic domain along with surveyed morphological changes (DHI, 2011).

The presence of an extensive natural outcrop of reef seaward of the study area required a nested wave model to be developed for Palm Beach. A regional wave model grid and three nested wave grids with progressively increasing resolution were constructed. A hydrodynamic model grid was nested within the smallest Palm Beach wave grid. The bathymetry for the grids are derived from the City of Gold Coast's hydrographic survey data and a multibeam survey of the Palm Beach natural reef, collected in 2012.

\section{RESULTS}

Preliminary wave and hydrodynamic model results show good agreement with the nearshore water levels (Figure 3) and waves (Figure 4 and Figure 5) for a period coinciding with an in-situ ADCP deployment at a depth of approximately $-7 \mathrm{~m}$ AHD (Australian Height Datum, which is locally approximately equivalent to Mean Sea Level (MSL)). A battery change resulted in a gap in the recorded data in Figure 5.

The highest error is an underestimation of wave height by the model up to $30 \mathrm{~cm}$ for the larger waves in the sample. This may be accounted for by local wind effects which were not included in this model given that the Gold Coast wave climate is primarily swell dominated.

However, agreement between the modelled currents and insitu current data was poor. Overall, measured current speeds and waves however were quite low for the observed period suggesting that the ADCP was too far seaward to record the strongest wavedriven currents responsible for morphological changes. Figure 6 compares the wind speed recorded by the closest coastal

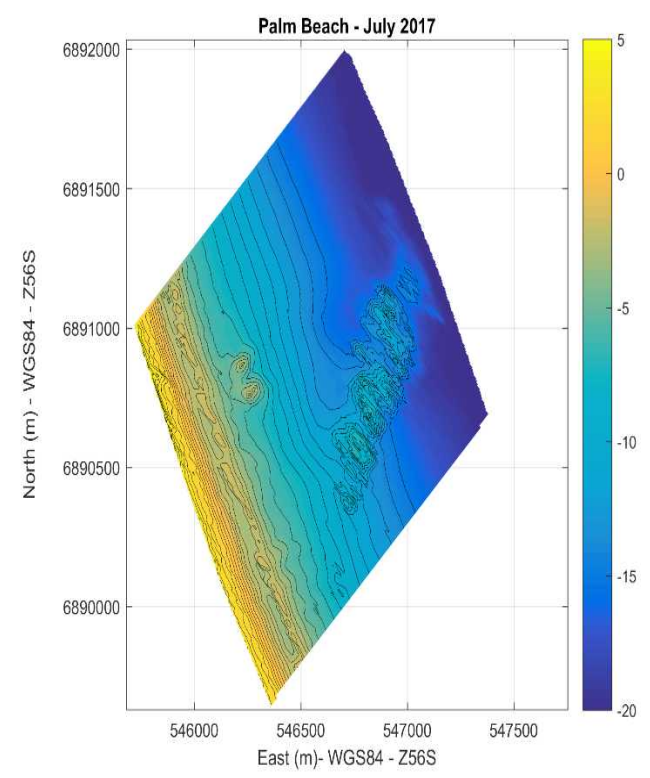

Figure 1. Surveyed morphology shortly after beach nourishment, July 2017.

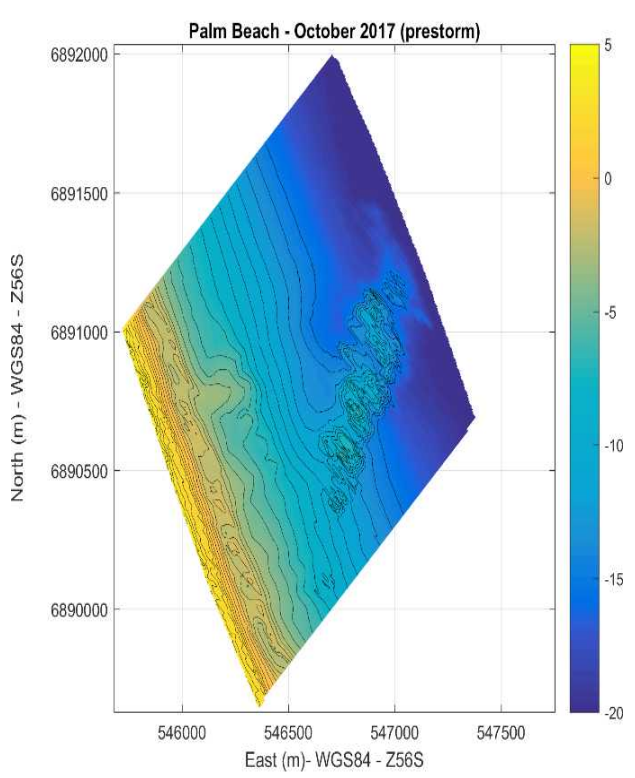

Figure 2. Surveyed morphology 4 months after beach nourishment, October 2017. 


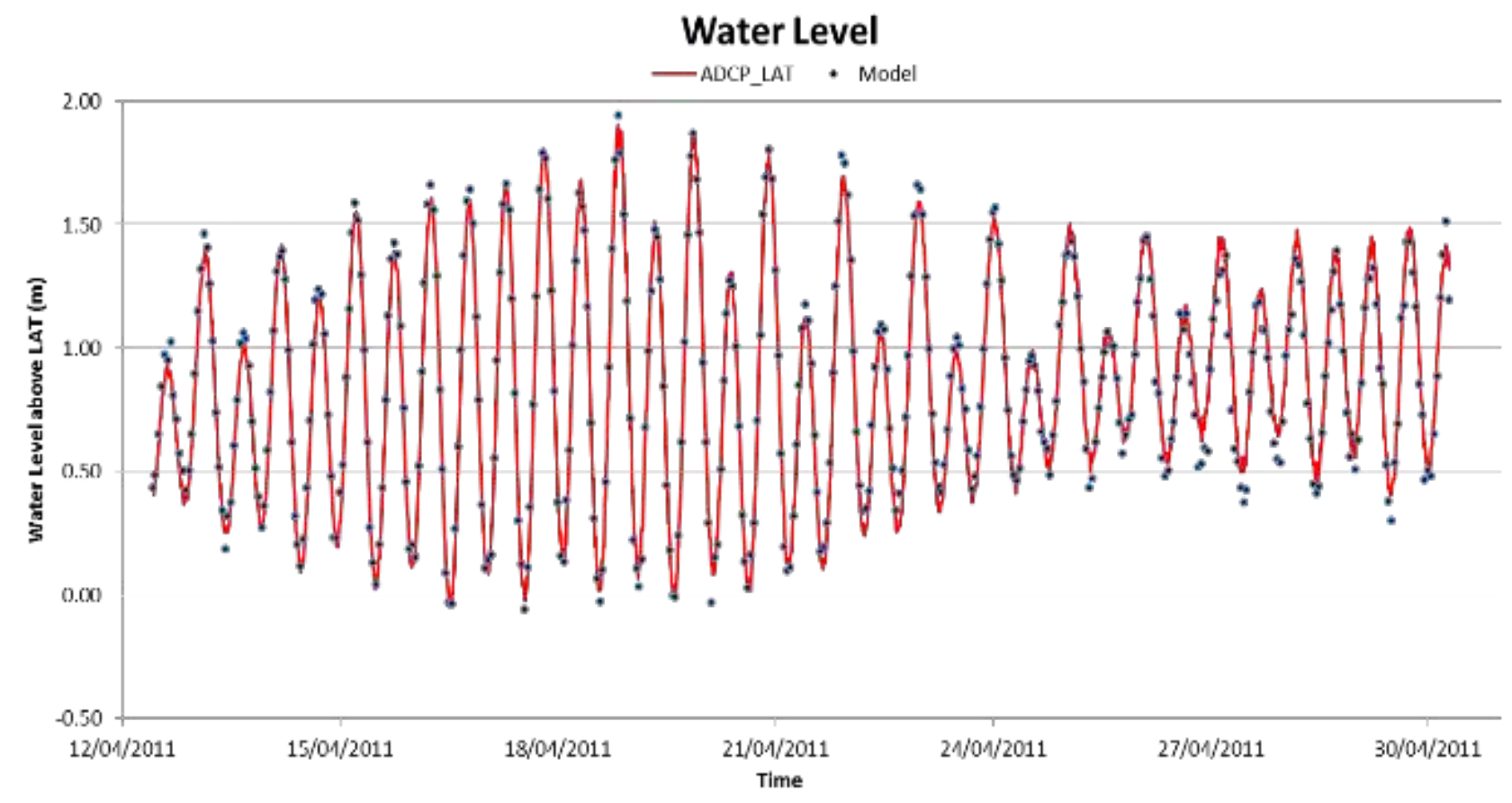

Figure 3. Modelled and measured water levels.
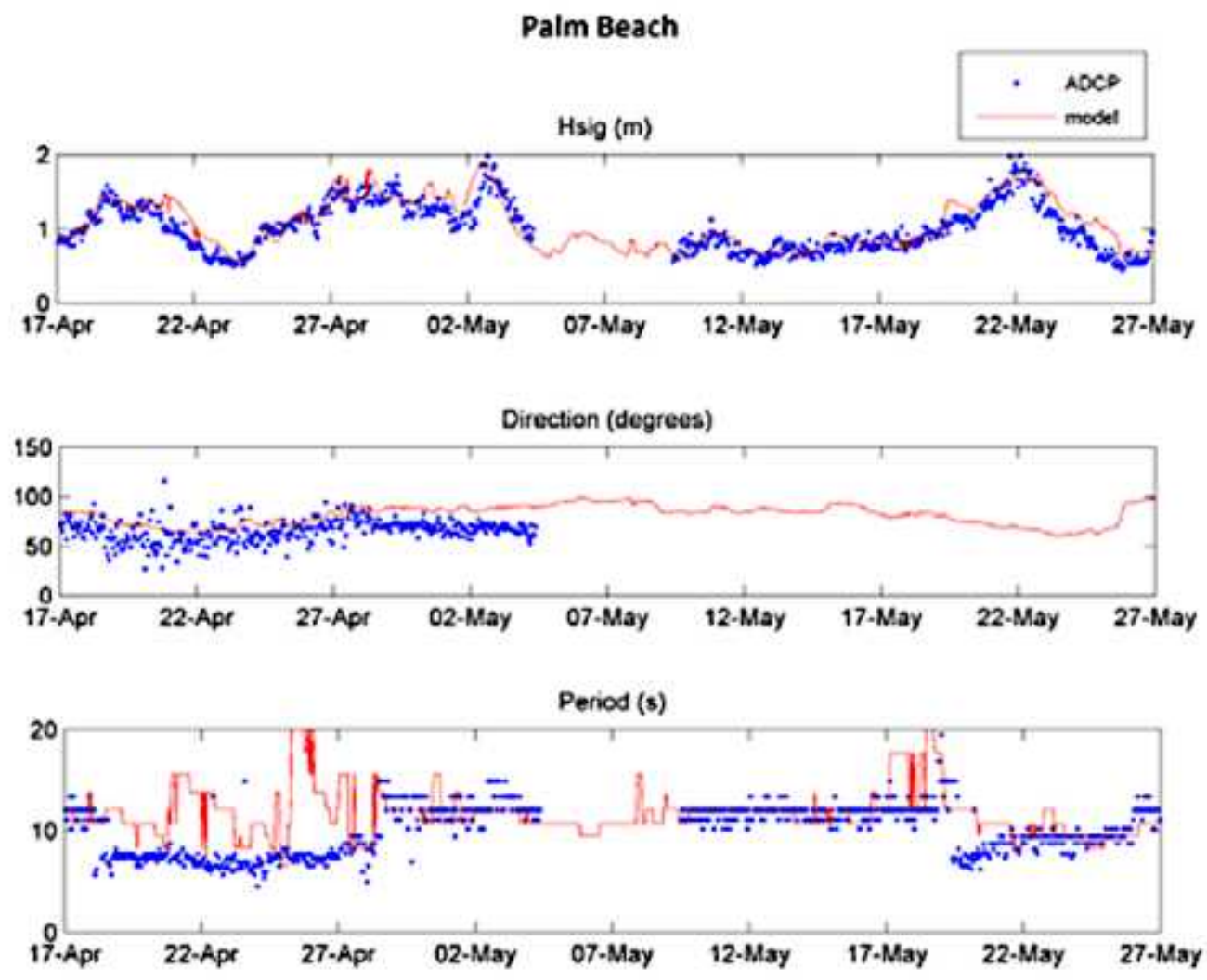

Figure 4. Modelled and measured wave parameters at the location of the in-situ ADCP. 


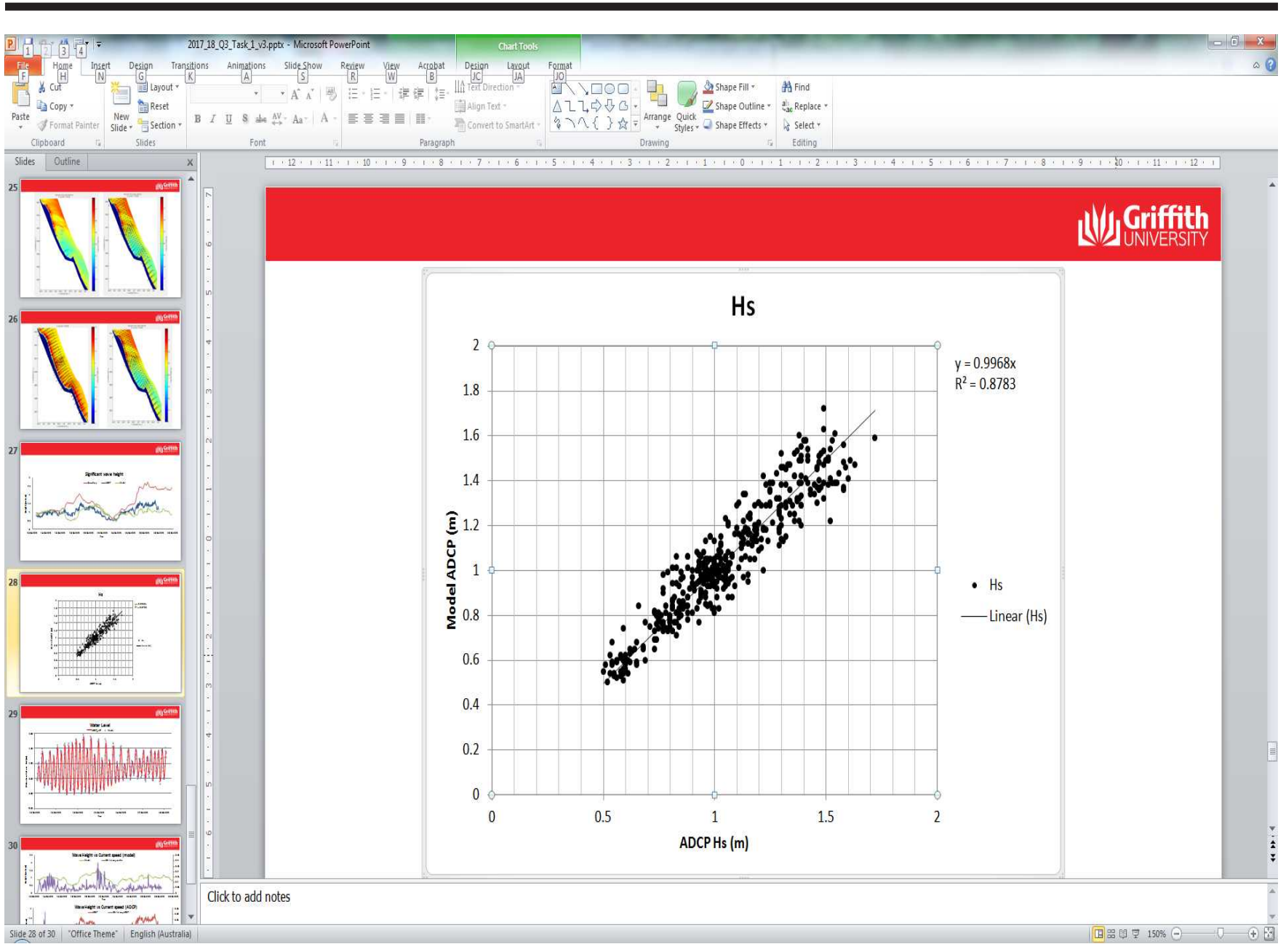

Figure 5. Comparison between modelled and measured wave height at the Palm Beach ADCP location (2011).

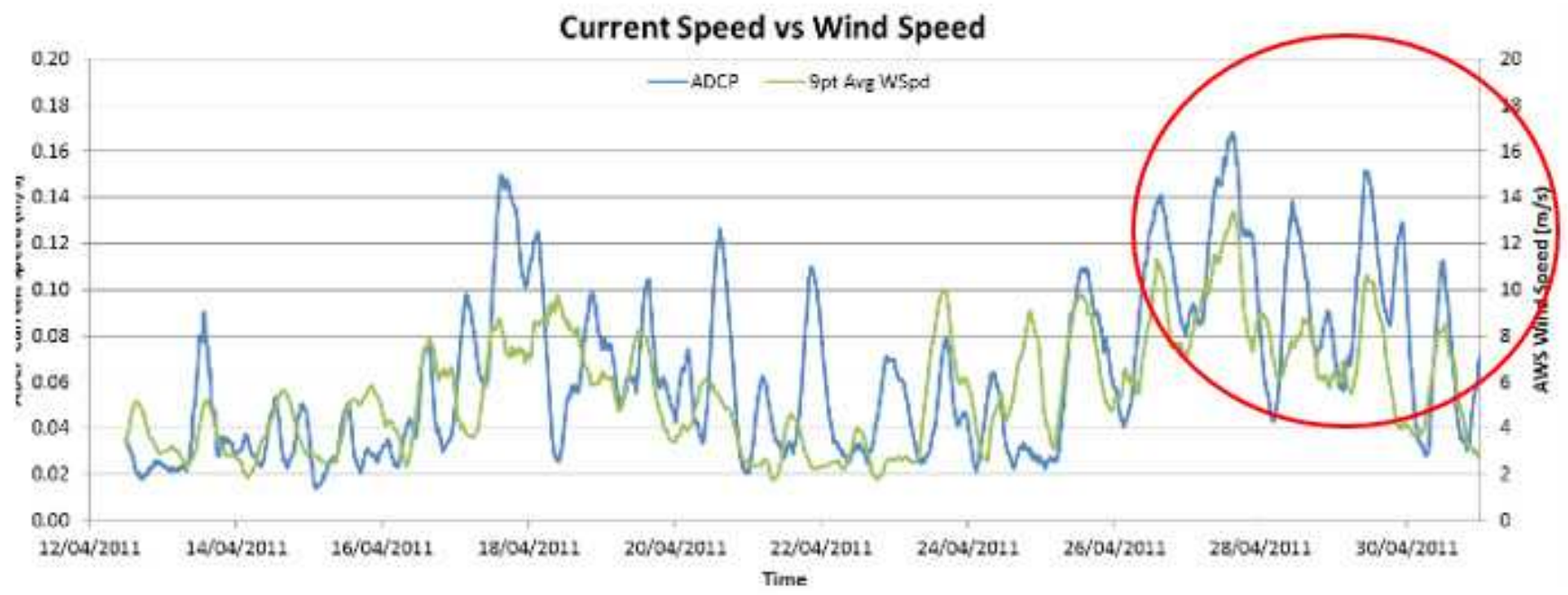

Figure 6. 23 Measured current speed (ADCP) vs measured wind speed (GC AWS).

Automatic Weather Station (AWS), approximately $22 \mathrm{~km}$ to the north, and suggests there is a relationship between the higher wind speeds and currents recorded by the ADCP towards the end of the measurement period (Figure 6, red circle). 
A good qualitative agreement of observed and modelled morphological changes at the nourishment site was attained for the 104 day period between successive surveys (before and following nourishment). The upper $2 \mathrm{~m}$ of the modelled nourishment mound was transported shoreward and northwards, merging with the inner beach bar around the 2-4 $\mathrm{m}$ depth contour (Figure 7).

\section{DISCUSSION}

Measured and modelled depth-averaged current speeds were compared at the location of the deployed ADCP for the measurement period. It should be noted that he measured current speeds were quite low during this time. The modelled currents speeds vary within a similar range and are also quite low but do not agree well with the measurements. This is considered likely to be due to the depth of the ADCP (-7 m AHD) and the relatively low wave energy during the measurement period. The model is only forced by waves and tide and the model represents the tidal variations quite well.

The depth of the instrument is such that it was unlikely to record wave generated currents responsible for the bulk of the sediment transport (which is mainly confined to the surf zone) so that the measured current speeds may be more closely linked to wind
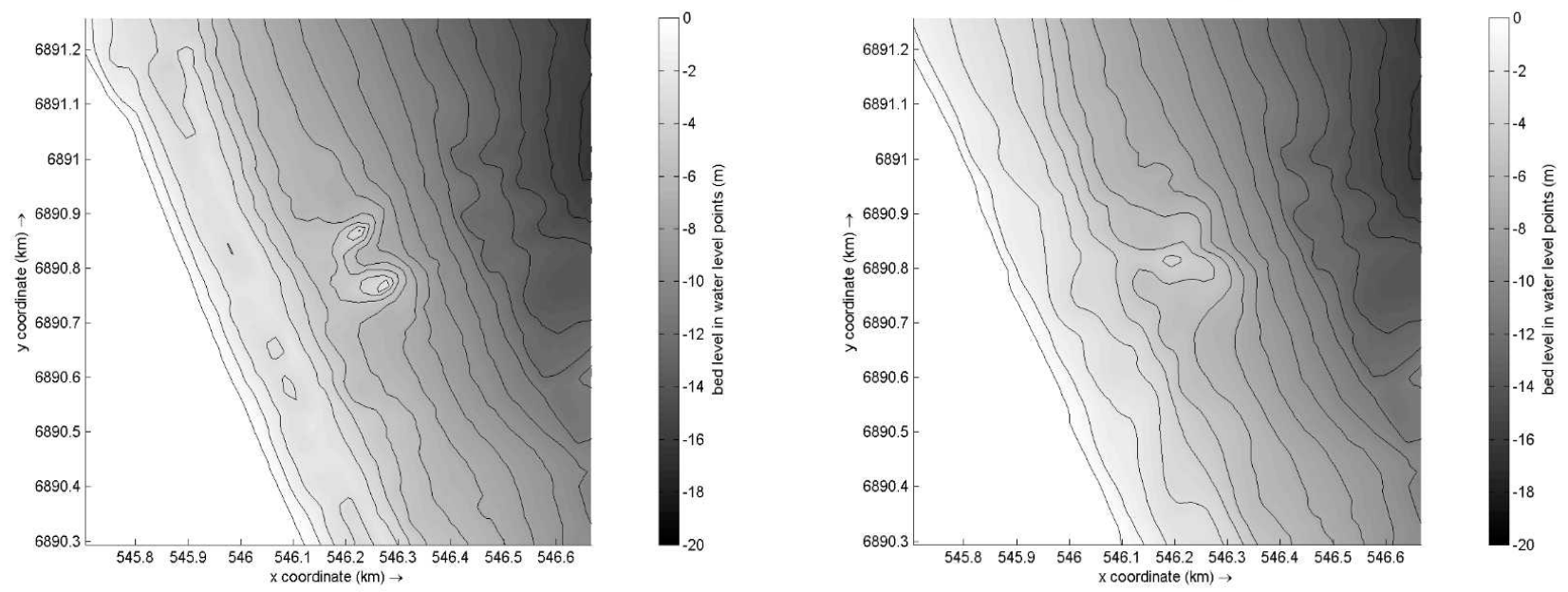

Figure 7. Morphological model initial bathymetry, July 2017 (left) and final bathymetry, October, 2017 (right) showing the dispersion of the nourishment.
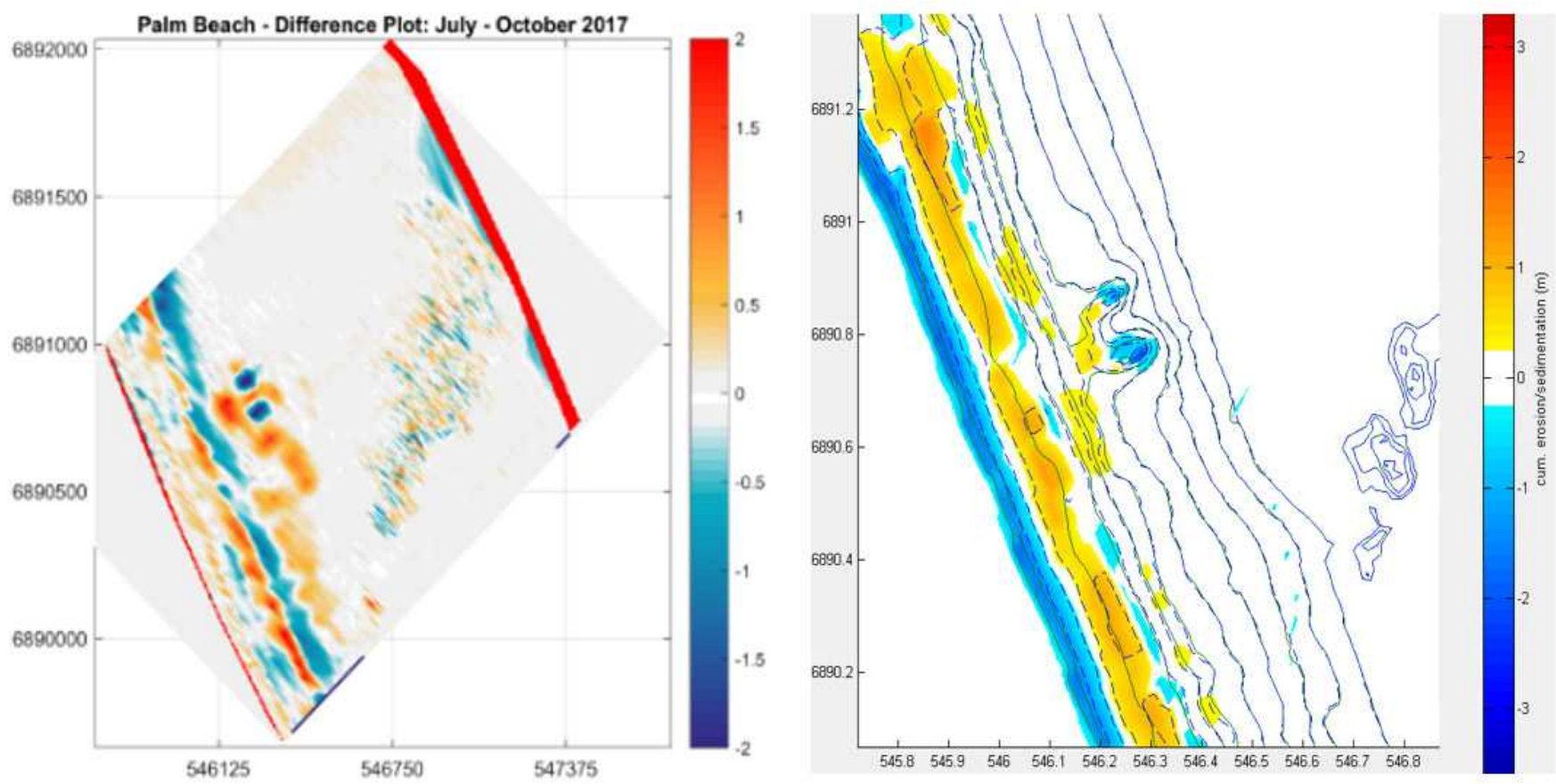

Figure 8. Morphological changes, measured (left), modelled (right). 
stress rather than shoaling and breaking waves. However, onshore wave-induced transport may still occur at this depth and increase shoreward until the undertow becomes the dominant mechanism. A cross-shore array of instruments would be beneficial for a better understanding of the cross-shore distribution of surf zone currents.

\section{CONCLUSIONS}

In order to validate the wave transformation from deep water to the surf zone a numerical wave model of Palm Beach was developed using bathymetry from 2011 to coincide with 2 months of in-situ measurements of wave, currents and water levels collected from April to May 2011. Numerous surveys were collected by the City of Gold Coast at Palm Beach during and immediately after the 2017 large scale beach nourishment project which were used to test a model of the dispersion of the nourishment from a section of the surf zone of Palm Beach.

Modelled significant wave heights, mean wave direction and water levels compared well with those measured by the ADCP however modelled current speeds did not compare well. The measured current speeds at the deployment depth of -7 m AHD (seaward of the surf zone) were quite low during this time.

In the absence of relevant measured surf zone currents the next stage of the model validation focused on the morphological changes observed after the nearshore nourishment at Palm Beach. The application of a Delft3D morphological model was able to simulate the shoreward and alongshore transport of a deposition of sand in the outer surf zone qualitatitively. In 2019 a multi-purpose artificial reef was constructed at this site and it's morphological response is currently the focus of ongoing monitoring efforts.

\section{ACKNOWLEDGEMENTS}

This research project was sponsored by the City of Gold Coast (the City) through a funding and collaboration agreement between the City and Griffith University. The City has provided data, including bathymetric survey, and project overview to assist in the understanding of this research topic and its benefit to the City. This research was also supported by an Advance Queensland Research Fellowship, number AQRF02815-16RD1.

\section{LITERATURE CITED}

Chang, Y.S.; Huisman, B.; de Boer, W., and Yoo, J., 2018. Hindcast of long-term shoreline change due to coastal interventions at Namhangjin, Korea. Journal of Coastal Research: Special Issue 85 - Proceedings of the 15th International Coastal Symposium: pp. 201-205.

DHI, 2011. Gold Coast Shoreline Management Plan Field Measurement \& Data Collection Technical Report. Gold Coast City Council Technical Report June 2011

Jackson, L.A. and Tomlinson, R.B., 1990. Nearshore nourishment: Implementation, monitoring and model studies of the $1.5 \mathrm{M}$ M3 at Kirra beach. Proceedings of the 27th International Conference on Coastal Engineering.

Shaeri, S.; Strauss, D.; Etemad-Shahidi, A., and Tomlinson, R., 2018. Hydrosedimentological modelling of a small, trained tidal inlet system, currumbin creek, southeast Queensland, Australia. Journal of Coastal Research, 34(2), 341-359.

Smith, S. and Jackson, L.A., 1990. The siting of beach nourishment placements. Shore \& Beach Journal, 58(1). 